\title{
Negative Ion Photoelectron Spectroscopy Confirms the Prediction of a Singlet Ground State for the 1,8-Naphthoquinone Diradical
}

\author{
Zheng Yang, ${ }^{\S}$ David A. Hrovat, ${ }^{\dagger}$ Gao-Lei Hou, ${ }^{\S}$ Weston Thatcher Borden ${ }^{* \dagger}$ and \\ Xue-Bin Wang*§ \\ $\S$ Physical Sciences Division, Pacific Northwest National Laboratory, P. O. Box \\ 999, MS K8-88, Richland, WA 99352, USA \\ $\dagger^{\dagger}$ Department of Chemistry and the Center for Advanced, Scientific Computing and \\ Modeling, University of North Texas, 1155 Union Circle, \#305070, Denton, Texas \\ 76203-5070, USA
}

\section{Corresponding Authors}

Xue-Bin Wang: Xuebin.wang@pnnl.gov

Weston T. Borden: Weston.Borden@unt.edu 


\begin{abstract}
Negative ion photoelectron (NIPE) spectra, with 193, 266, 300, and $355 \mathrm{~nm}$ photons, of the radical anion of 1,8-naphthoquinone $\left(1,8-\mathbf{N Q}^{--}\right)$have been obtained at 20K. The electron affinity of 1,8-NQ is determined from the first resolved peak in the NIPE spectrum to be $2.965 \pm 0.005 \mathrm{eV}$. Franck-Condon factors (FCFs), calculated from the CASPT2/aug-cc-pVDZ optimized geometries, normal modes, and vibrational frequencies successfully simulate the intensity and frequencies of the spectral features that are associated with the lowest two electronic states. The NIPE spectra of 1,8-NQ ${ }^{--}$ and the peak assignments, based on the computed FCFs, confirm the theoretical predictions that ${ }^{1} \mathrm{~A}_{1}$ is the ground state of 1,8 - NQ and that ${ }^{3} \mathrm{~B}_{2}$ is the first excited state. The spectra provide an experimental value of $\Delta E_{S T}=-0.6 \mathrm{kcal} / \mathrm{mol}$, which is $2 \mathrm{kcal} / \mathrm{mol}$ smaller in magnitude than the (12/12)CASPT2/aug-cc-pVTZ calculated value of $\Delta E_{S T}=$ $-2.6 \mathrm{kcal} / \mathrm{mol}$.
\end{abstract}




\section{Introduction}

The single-triplet energy separations in diradicals have been of interest for many decades. ${ }^{1-12}$ Among the diradicals that have been studied, the isomeric benzoquinones (BQs) have been of particular interest. ${ }^{13-20}$ Both $o$ - and $p$-BQ have a singlet ground state; whereas, the ground state of $m-\mathbf{B Q}$ is a triplet. A triplet ground state for $m-\mathbf{B Q}$ was first predicted computationally ${ }^{14}$ and then confirmed experimentally by negative ion photoelectron (NIPE) spectroscopy of the corresponding radical anion $\left(m-\mathbf{B Q} \mathbf{Q}^{--}\right){ }^{18,20}$

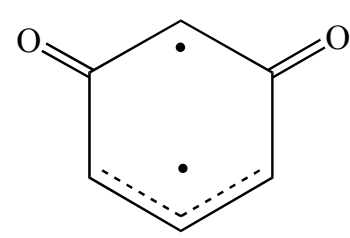

$m-\mathbf{B Q}$

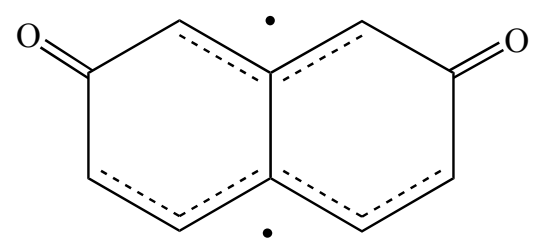

2,7-NQ

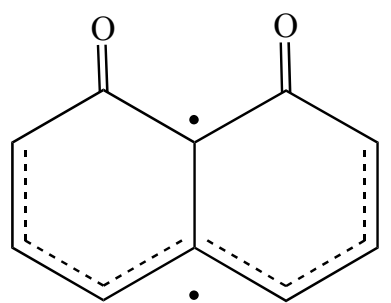

$1,8-\mathbf{N Q}$

Figure 1. The structures of the meta-benzoquinone ( $m$-BQ), 2,7-naphthoquinone (2,7NQ), and 1,8-naphthoquinone (1,8-NQ) diradicals.

The NIPE spectra of $o$ - and $p$-BQ $\mathbf{B}^{--}$each reveal a broad ground-state feature and a large band gap, followed by well-resolved excited state peaks, in the neutral molecule. ${ }^{18}$ In contrast, the NIPE spectrum of $m-\mathbf{B Q}^{--}$is distinctly different from those of its two isomers, showing no clear band gap, a much higher electron affinity (EA) (2.89 eV), and a triplet ground state. ${ }^{18,20}$ Calculations not only predicted the triplet ground state of $m$-BQ but also the relative energies of the low-lying singlet electronic states of $m$-BQ. ${ }^{14}$ These predictions were confirmed by the good agreement between Franck-Condon simulations of the NIPE spectrum of $m-\mathbf{B Q}^{--}$and the experimental spectrum. ${ }^{20}$

The 2,7-naphthoquinone (2,7-NQ) diradical has also been studied both theoretically and experimentally. ${ }^{21,22}$ A triplet ground state $\left({ }^{3} \mathrm{~B}_{2}\right)$ was predicted by CASPT2 calculations, ${ }^{21}$ and this prediction was subsequently confirmed by NIPE spectroscopy on the corresponding radical anion $\left(2,7-\mathbf{N Q}^{\bullet-}\right){ }^{22}$ 
It would be natural to assume that the isomeric 1,8-naphthoquinone (1,8-NQ) diradical also has a triplet ground state. Like 2,7-NQ, 1,8-NQ is a non-Kekulé quinone, (i.e, a quinone for which no Kekulé structures can be written that do not contain at least two unpaired electrons). ${ }^{23}$ However, a recent theoretical study made the surprising prediction that 1,8-NQ differs from 2,7-NQ by not having a triplet ground state. ${ }^{24}$ Instead the ground state of $1,8-\mathrm{NQ}$ was predicted to be a singlet $\left({ }^{1} \mathrm{~A}_{1}\right)$, with the lowest triplet $\left({ }^{3} \mathrm{~B}_{2}\right)$ state calculated to be $2.6 \mathrm{kcal} / \mathrm{mole}$ higher in energy.

The reason for this surprising prediction is that, of the two MOs that are singly occupied in the triplet state of $1,8-\mathbf{N Q}$, the $b_{1} \pi \mathrm{MO}$ is calculated to be considerably lower in energy than the $a_{2} \pi$ MO. This energy difference, which is computed to amount to 19.5 $\mathrm{kcal} / \mathrm{mol}$ in the $1,8-\mathbf{N Q}$ radical anion $\left(1,8-\mathbf{N Q}^{--}\right)$, is a consequence of the fact that, as shown in Figure 2, the $b_{1} \pi M O$ has one fewer nodal plane than the $a_{2} \pi M O$. As a result, the double occupancy of the $b_{1} \pi$ MO in the lowest singlet state is computed to be favored over the single occupancy of the $b_{1}$ and $a_{2} \pi$ MOs in the lowest triplet state.

The calculations make another interesting prediction. The proximity of the two oxygen atoms in 1,8-NQ results in the out-of-phase combination of the two oxygen $2 \mathrm{p}-\sigma$ AOs in the $b_{2} \sigma \mathrm{MO}$ destabilizing this MO. This MO, which is also shown in Figure 2, is calculated to be higher in energy (by $6.8 \mathrm{kcal} / \mathrm{mol}$ in $1,8-\mathbf{N Q}^{\circ-}$ ) than the $\mathrm{b}_{1} \pi \mathrm{MO}$.

The exchange integral between two $\pi$ MOs is much larger than that between a $\sigma$ and a $\pi \mathrm{MO}$; so the lowest triplet state of $1,8-\mathbf{N Q}$ is ${ }^{3} \mathrm{~B}_{2}$, which has the $\mathrm{b}_{2} \sigma \mathrm{MO}$ doubly occupied and the unpaired electrons in the $b_{1}$ and $a_{2} \pi$ MOs. Nevertheless, the lower oneelectron energy of the $b_{1} \pi$ MO than of the $b_{2} \sigma$ MO makes the energy computed for the ${ }^{3} \mathrm{~B}_{1}$ state, in which the $b_{1} \pi \mathrm{MO}$ is doubly occupied and the unpaired electrons occupy the $\mathrm{b}_{2} \sigma$ and $\mathrm{a}_{2} \pi$ MOs, only $6.0 \mathrm{kcal} / \mathrm{mol}$ higher than that of the ${ }^{3} \mathrm{~B}_{2}$ state of $1,8-\mathbf{N Q}$.

Thus, unlike the case in 2,7-NQ, ${ }^{21,22}$ calculations predict that not only should 1,8NQ have a singlet ground state but there should be a second triplet state that is very close in energy to the lowest triplet state. ${ }^{24}$ The NIPES experiments described in this paper were undertaken in order to verify these two predictions. 


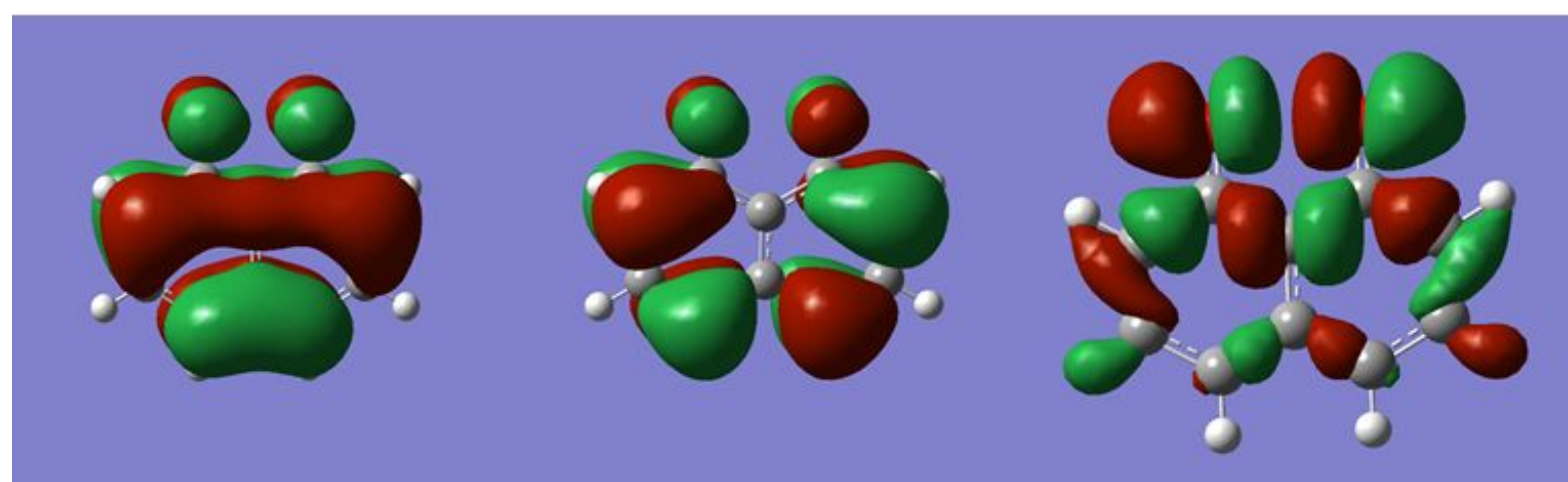

Figure 2. The $b_{1}$ (left) and $a_{2}$ (center) $\pi$ MOs and the $b_{2}$ (right), oxygen, $2 p$ $\sigma$ lone-pair MO of 1,8-NQ. The $b_{2} \sigma \mathrm{MO}$ and the $\mathrm{a}_{2} \pi \mathrm{MO}$ are calculated to be, respectively, 6.8 , and $19.5 \mathrm{kcal} / \mathrm{mol}$ higher in energy than the $b_{1} \pi \mathrm{MO}$ in $1,8-\mathrm{NQ}^{\cdot-} .{ }^{24}$

\section{Experimental Methodology}

The negative ion photoelectron spectroscopy (NIPES) experiments were carried out at PNNL using an apparatus consisting of an electrospray ionization (ESI) source, a temperature controlled cryogenic ion trap, and a magnetic-bottle time-of-flight (TOF) photoelectron spectrometer. ${ }^{25}$ A $0.1 \mathrm{mM}$ acetonitrile solution of 1,8-dihydroxynaphalene, titrated with a small amount of $\mathrm{NaOH}$ dissolved in water, was prepared in a $\mathrm{N}_{2}$ glovebox, and used to generate $1,8-\mathbf{N Q}^{-}$by electrospray under an $\mathrm{N}_{2}$ atmosphere. The inert $\mathrm{N}_{2}$ environment helps reduce unwanted radical reactions in solution and in the sprayed droplets, thus helping to generate strong and stable ion beams. The ESI conditions were optimized to ensure that the doubly deprotonated species, $1,8-\mathbf{N Q}^{-}$, was a prominent peak in the mass spectrum.

The ions generated by ESI were guided by quadrupole ion guides into the ion trap, where they were accumulated and cooled for $20-100 \mathrm{~ms}$ by collisions with cold buffer gas $\left(20 \% \mathrm{H}_{2}\right.$ balanced in helium) at $20 \mathrm{~K}$, before being transferred into the extraction zone of a TOF mass spectrometer. The cooling of the anions to $20 \mathrm{~K}$ improved the spectral energy resolution and minimized the possibility of the appearance of peaks in the NIPE spectra resulting from hot bands.

The 1,8-NQ ${ }^{--}$ions were then mass selected and maximally decelerated before being photodetached. In the current study, photon energies of $193 \mathrm{~nm}(6.424 \mathrm{eV})$ from an 
excimer laser, $266 \mathrm{~nm}(4.661 \mathrm{eV})$ and $355 \mathrm{~nm}(3.496 \mathrm{eV})$ from a Nd:YAG laser, and 300 $\mathrm{nm}(4.133 \mathrm{eV})$ from doubling frequency of $600 \mathrm{~nm}$ photons from an OPO/OPA laser were used. The lasers were operated at a $20 \mathrm{~Hz}$ repetition rate, with the ion beam off at alternating laser shots, in order to enable shot-to-shot background subtraction.

Photoelectrons were collected with ca. 100\% efficiency with the magnetic bottle and analyzed in a $5.2 \mathrm{~m}$ long electron-flight tube. The recorded TOF photoelectron spectrum was converted into an electron kinetic-energy spectrum by calibration with the known NIPE spectra of $\mathrm{I}^{-26}$ and $\mathrm{OsCl}_{6}{ }^{2-} \cdot{ }^{27}$ The electron-binding energy (EBE) was obtained by subtracting the electron kinetic energy from the energy of the detaching photons. The energy resolution was about $2 \%$ (i.e., $\sim 20 \mathrm{meV}$ for $1 \mathrm{eV}$ kinetic-energy electrons).

\section{Computational Methodology}

The geometries, normal modes, and frequencies of 1,8-NQ and 1,8-NQ ${ }^{--}$were calculated at the CASPT2/aug-cc-pVDZ level of theory ${ }^{28,29}$ using the MOLCAS version 8.0 suite of programs. ${ }^{30}$ An active space that correlated 12 or 13 electrons in the twelve $\pi$ MOs was used for electronic states in which the $b_{2} \sigma$ MO was doubly occupied. For electronic states in which the $\mathrm{b}_{2} \sigma \mathrm{MO}$ was singly occupied a fourteen orbital active space was used in which 16 or 17 electrons were correlated in the two p- $\sigma$ lone pair MOs on oxygen in addition to the $12 \pi$-MOs. ${ }^{24}$ Franck-Condon factors (FCFs), including Duschinsky rotations, were calculated from the CASPT2/aug-cc-pVDZ optimized geometries, normal modes, and frequencies for totally symmetric $\left(\mathrm{a}_{1}\right)$ vibrations, using the ezSpectrum (version 3.0) program, developed by Mozhayskiy and Krylov. ${ }^{31}$

\section{Results and Discussion}

\section{Photoelectron spectrum of 1,8-NQ*-}

The NIPES experiments were first carried out at 355 and $266 \mathrm{~nm}$. Two sets of spectra were obtained at each wavelength, dependent on different spraying conditions. At $355 \mathrm{~nm}$, a spectrum with a dominant, 1st peak at $\mathrm{EBE}=2.85 \mathrm{eV}$ was obtained when spraying under air and with higher ESI voltages (blue curve in Figure S1 in the Supporting materials). In contrast, under N2 environment and milder spraying voltages, a distinctly different spectrum with significant gain in intensity for $\mathrm{EBE} \geq 3.0 \mathrm{eV}$ features 
was obtained (red curve in Figure S1) with appreciable contribution from the blue spectrum. The blue spectrum is mostly like derived from an unknown species with identical $\mathrm{m} / \mathrm{z}$ as $1,8-\mathbf{N Q}^{--}$, generated under the hash spraying conditions (with air and higher voltages). Similar phenomenon occurred at $266 \mathrm{~nm}$, but the contribution from the contamination (blue spectrum in Figure S2) is reduced. However, even under N2 and with milder voltages, this unknown species still exists and contributes to the spectra. The corrected 355 and $266 \mathrm{~nm}$ NIPE spectra of 1,8-NQ ${ }^{-}$presented in the text were obtained by subtracting this contamination. With acknowledging this impurity issue, the NIPES experiments at 300 and $193 \mathrm{~nm}$ were carried out by carefully optimizing spraying conditions to minimizing the contamination, gauged by minimizing the $\mathrm{EBE}=2.85 \mathrm{eV}$ peak.

The NIPE spectra of 1,8-NQ- with 355, 300, 266, and $193 \mathrm{~nm}$ photon are shown in Figure 3. 


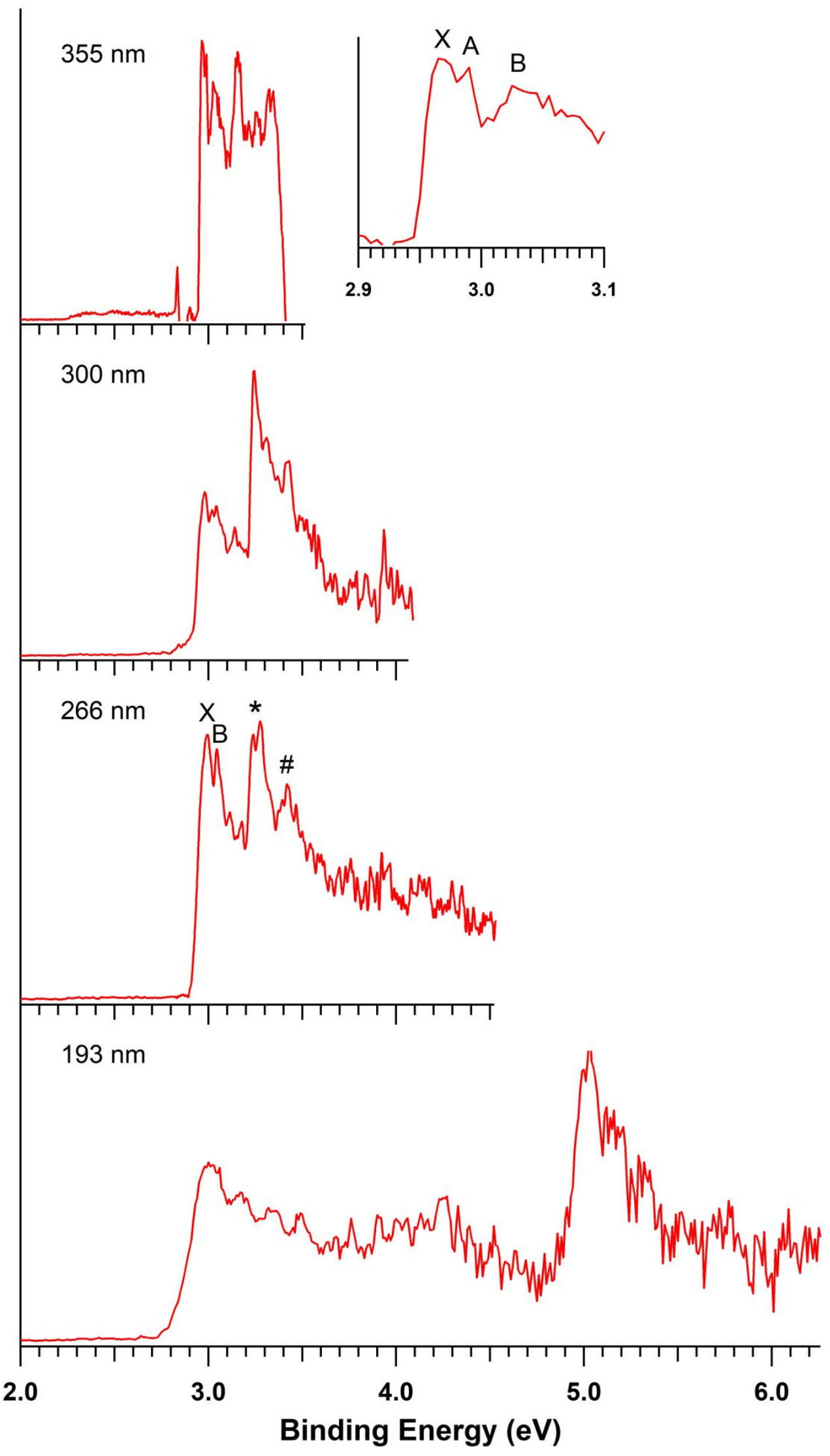


Figure 3. The $20 \mathrm{~K}$ NIPE spectra of 1,8-NQ- at 355, 300, 266, and $193 \mathrm{~nm}$. The $355 \mathrm{~nm}$ spectrum shows the "X peak", which is unresolved at all other wavelengths, split into two peaks. The expanded spectrum to the right shows the origin of the $\mathrm{X}$ peak at $\mathrm{EBE}=2.965$ $\mathrm{eV}$ and a second peak, A, at $2.990 \mathrm{eV}$. The small peak in between 2.6 and $2.7 \mathrm{eV}$ in the $355 \mathrm{~nm}$ spectrum is from the imperfect subtraction of an unknown impurity (see Figure $\mathrm{S} 1$ in the Supporting Information), and the tiny peak at $\sim 2.85 \mathrm{eV}$ at $300 \mathrm{~nm}$ is from this unknown impurity.

Several sharp features are seen in the $266 \mathrm{~nm}$ spectrum in the EBE range from c.a. $2.9 \mathrm{eV}$ to $3.5 \mathrm{eV}$. The lowest energy and highest intensity peak is at EBE $2.99 \mathrm{eV}$ and marked as X. Next to it at EBE $3.045 \mathrm{eV}$ is a slightly lower intensity peak, marked as B. Band $\mathrm{X}$ is noticeably broader than peak $\mathrm{B}$. At EBE $3.24 \mathrm{eV}$ and $3.42 \mathrm{eV}$ are two strong features, marked as * and \#, respectively. The spectrum becomes an unresolved continuum band after \#.

At $300 \mathrm{~nm}$, the $\mathrm{X}$ and $\mathrm{B}$ bands are similar to those observed at $266 \mathrm{~nm}$, but peak * becomes a much more intense and dominant peak in the spectrum. With $193 \mathrm{~nm}$ photons, additional spectral bands with higher EBEs, e.g., a band at $\mathrm{EBE}=5 \mathrm{eV}$, are visible.

More sharp peaks are resolved in the $355 \mathrm{~nm}$ spectrum, in which the intrinsic instrumental resolution is highest. Most importantly, band X, which is unresolved at other wavelengths, at $355 \mathrm{~nm}$ splits into two peaks. The expanded spectrum at the top of Figure 3 shows that the origin of the $\mathrm{X}$ peak is at $\mathrm{EBE}=2.965 \mathrm{eV}$; and the second peak, $\mathrm{A}$, is at $2.990 \mathrm{eV}$.

\section{Assignment of the NIPE spectrum and Discussion}

According to the previous CASPT2 calculations, ${ }^{24}$ there are five low-lying electronic states of 1,8-NQ that might be observed in the NIPE spectrum of 1,8-NQ ${ }^{-}$. These states and their CASPT2 energies, relative to the ${ }^{2} \mathrm{~A}_{2}$ state of $1,8-\mathrm{NQ}^{-}$are listed in Table 1. 
Table 1. The assignments of the major peaks in the NIPE spectrum of 1,8-NQ*- and the experimental electron binding energy $(E B E)(\mathrm{eV})$ of each. The CASPT2/aug-cc-pVTZ relative energies $(\Delta E$ in $\mathrm{eV})$ of the low-lying electronic states of 1,8-NQ ${ }^{-}$and 1,8-NQ from ref. 24 are given for comparison with the experimental binding energies.

\begin{tabular}{|l|l|c|c|c|}
\hline Species & Electronic State & $\Delta E$ (CASPT2) & \multicolumn{2}{|c|}{ NIPES EBE } \\
\hline $1,8-\mathbf{N Q}^{-}$ & ${ }^{2} \mathrm{~A}_{2}=\mid \ldots \mathrm{b}_{2}{ }^{2} \mathrm{~b}_{1}{ }^{2} \mathrm{a}_{2}{ }^{\alpha}>$ & 0 & 0 & 0 \\
\hline $1,8-\mathrm{NQ}$ & ${ }^{1} \mathrm{~A}_{1}=\mathrm{c}_{1}\left|\ldots \mathrm{b}_{2}{ }^{2} \mathrm{~b}_{1}{ }^{2}>-\mathrm{c}_{2}\right| \ldots \mathrm{b}_{2}{ }^{2} \mathrm{a}_{2}{ }^{2}>$ & $2.957^{\mathrm{a}}$ & $\mathrm{X}, 2.98^{\mathrm{c}}$ & $\mathrm{X}, 2.965^{\mathrm{d}}$ \\
\hline & ${ }^{3} \mathrm{~B}_{2}=\mid \ldots \mathrm{b}_{2}{ }^{2} \mathrm{~b}_{1} \mathrm{a}_{2}(\alpha \beta+\beta \alpha) / \sqrt{2}>$ & $3.070^{\mathrm{a}}$ & $\mathrm{B}, 3.045$ & $\mathrm{~A}, 2.990$ \\
\hline & ${ }^{3} \mathrm{~B}_{1}=\mid \ldots \mathrm{b}_{1}{ }^{2} \mathrm{~b}_{2} \mathrm{a}_{2}(\alpha \beta+\beta \alpha) / \sqrt{2}>$ & $3.330^{\mathrm{b}}$ & $*, 3.24$ & $*, 3.24$ \\
\hline & ${ }^{1} \mathrm{~B}_{1}=\mid \ldots \mathrm{b}_{1}{ }^{2} \mathrm{~b}_{2} \mathrm{a}_{2}(\alpha \beta-\beta \alpha) / \sqrt{2}>$ & $3.408^{\mathrm{b}}$ & $\#, 3.42$ & $\#, 3.42$ \\
\hline & ${ }^{1} \mathrm{~B}_{2}=\mid \ldots \mathrm{b}_{2}{ }^{2} \mathrm{~b}_{1} \mathrm{a}_{2}(\alpha \beta-\beta \alpha) / \sqrt{2}>$ & $4.133^{\mathrm{a}}$ & $>3.5$ & $>3.5$ \\
\hline
\end{tabular}

a (12/12)CASPT2/aug-cc-PVTZ//(12/12)CASPT2/aug-cc-PVDZ

b(16/14)CASPT2/aug-cc-pVTZ//(16/14)CASPT2/aug-cc-pVDZ, combined with the CCSDT/aug-cc-pVTZ energy difference of $0.26 \mathrm{eV}$ between ${ }^{3} \mathrm{~B}_{1}$ and ${ }^{3} \mathrm{~B}_{2}$.

${ }^{\mathrm{c}}$ Assignment \#1 - assigning the average of EBEs of $\mathrm{X}$ and $\mathrm{A}$ to the ${ }^{1} \mathrm{~A}_{1}$ state, and peak $\mathrm{B}$ to ${ }^{3} \mathrm{~B}_{2}$.

${ }^{\mathrm{d}}$ Assignment \#2 - assigning peak $\mathrm{X}$ at $\mathrm{EBE}=2.965 \mathrm{eV}$ to the ${ }^{1} \mathrm{~A}_{1}$ state, peak $\mathrm{A}$ with $\mathrm{EBE}=2.990 \mathrm{eV}$ to ${ }^{3} \mathrm{~B}_{2}$, and peak $\mathrm{B}$ to a vibrational progression in ${ }^{3} \mathrm{~B}_{2}$.

The CASPT2 calculations predict that the ${ }^{1} \mathrm{~A}_{1}$ state is the ground state of $1,8-\mathbf{N Q}$; and just $0.1 \mathrm{eV}$ higher is the ${ }^{3} \mathrm{~B}_{2}$ state. The ${ }^{3} \mathrm{~B}_{1}$ state is calculated to have $E B E=3.330 \mathrm{eV}$, and the ${ }^{1} \mathrm{~B}_{1}$ state is computed to be less than $0.1 \mathrm{eV}$ higher than ${ }^{3} \mathrm{~B}_{1}$. The small exchange energy between electrons in the $b_{2} \sigma \mathrm{MO}$ and the $\mathrm{a}_{2} \pi \mathrm{MO}$ is responsible for the small calculated energy difference between the ${ }^{3} \mathrm{~B}_{1}$ and ${ }^{1} \mathrm{~B}_{1}$ states. ${ }^{24}$ The much larger exchange energy between electrons in the $b_{1} \pi \mathrm{MO}$ and the $\mathrm{a}_{2} \pi \mathrm{MO}$ is responsible for the much greater calculated energy difference of $1.06 \mathrm{eV}$ between the ${ }^{3} \mathrm{~B}_{2}$ and ${ }^{1} \mathrm{~B}_{2}$ states. 
Comparing the CASPT2 results with the experimental spectrum, if we neglected the small $\mathrm{X}-\mathrm{A}$ splitting in the $355 \mathrm{~nm}$ spectrum, we could assign the peak at $2.98 \mathrm{eV}$ (the average EBE value of $\mathrm{X}$ and $\mathrm{A}$ ) to the ${ }^{1} \mathrm{~A}_{1}$ state, and peak $\mathrm{B}$ at 3.045 to the nearby ${ }^{3} \mathrm{~B}_{2}$ state. This assignment (assignment \#1) would give experimental $E A$ and $\Delta E_{S T}$ values of, respectively, $2.98 \mathrm{eV}$ and $-1.5 \mathrm{kcal} / \mathrm{mol}$, compared with the (12/12)CASPT2/aug-cc$\mathrm{pVTZ}$ calculated values of $2.957 \mathrm{eV}$ and $\Delta E_{S T}=-2.6 \mathrm{kcal} / \mathrm{mol}$ (Table 1).

However, the splitting of peak $\mathrm{X}$, into $\mathrm{X}$ and $\mathrm{A}$, which is resolved in the $355 \mathrm{~nm}$ NIPE spectrum, leads us to assign $\mathrm{X}$ to the ${ }^{1} \mathrm{~A}_{1}$ state and $\mathrm{A}$ to the ${ }^{3} \mathrm{~B}_{2}$ state, yielding experimental values of $E A=2.965 \mathrm{eV}$ and $\Delta E_{S T}=-0.6 \mathrm{kcal} / \mathrm{mol}$ (assignment \#2). The adiabatic CASPT2 energy difference between ${ }^{2} \mathrm{~A}_{2}$ and ${ }^{3} \mathrm{~B}_{2}$, when combined with the $\operatorname{CCSD}(\mathrm{T})$ adiabatic energy difference of $0.26 \mathrm{eV}$ between ${ }^{3} \mathrm{~B}_{2}$ and ${ }^{3} \mathrm{~B}_{1}$ gives a predicted $E B E=3.33 \mathrm{eV}$ for ${ }^{3} \mathrm{~B}_{1}$, which is in reasonable agreement with the $E B E=3.24$ for peak * in the NIPE spectrum. As shown in Table 1, peak \# can be assigned to the ${ }^{1} \mathrm{~B}_{1}$ state.

\section{Franck-Condon Simulation of the NIPE spectra}

In order to further confirm the assignment of the electronic states of 1,8-NQ in the NIPE spectrum of 1,8-NQ ${ }^{-}$, the Franck-Condon factors (FCFs) for the transitions from the ${ }^{2} \mathrm{~A}_{2}$ state of $1,8-\mathbf{N Q}^{-}$to each of the low-lying states of $1,8-\mathbf{N Q}$ were calculated, using ezSpectrum. ${ }^{31}$ The simulated stick spectra were convoluted with Gaussian line broadening of the FCFs sticks for each transition. The results, based on assignments \#1 and \# 2, are shown in Figure 4 and Figure 5, respectively, where the simulated spectra have been superimposed on the $355,300,266$, and $193 \mathrm{~nm}$ experimental spectra for comparison. 


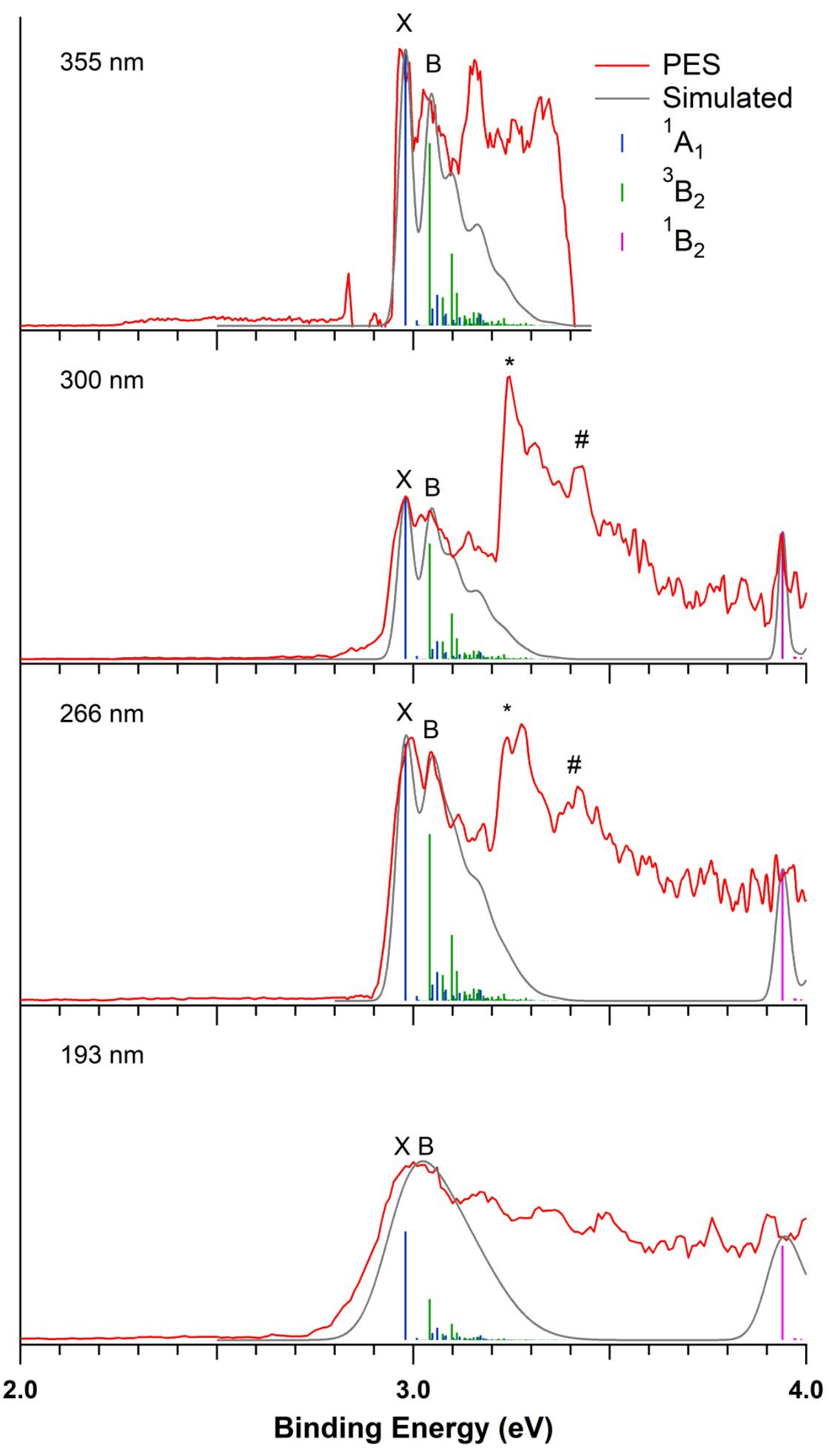

12

ACS Paragon Plus Environment 
Figure 4. Simulated NIPE spectra, based on assignment \# 1, for formation of the low-lying electronic states of 1,8-NQ, from 1,8-NQ ${ }^{-}$using the calculated CASPT2/aug-cc-pVDZ stick spectra, convoluted with Gaussian line broadening. The simulated spectra are superimposed onto the experimental spectra of 1,8-NQ ${ }^{-}$at 355, 300, 266, and $193 \mathrm{~nm}$. The simulated peak intensities and positions of the $0-0$ bands have been adjusted to match those in the experimental spectrum. The FWHMs of Gaussians for ${ }^{1} \mathrm{~A}_{1},{ }^{3} \mathrm{~B}_{2}$, and ${ }^{1} \mathrm{~B}_{2}$ peaks are set to $150,150,100 \mathrm{meV}$ for $193 \mathrm{~nm} ; 55,55$, and $40 \mathrm{meV}$ for $266 \mathrm{~nm} ; 45,45,25 \mathrm{meV}$ for $300 \mathrm{~nm}$; and 40, $40 \mathrm{meV}\left({ }^{1} \mathrm{~B}_{2}\right.$ doesn't show) for $355 \mathrm{~nm}$. No intensity is predicted by the FCFs for the transitions from the ${ }^{2} \mathrm{~A}_{2}$ state of $1,8-\mathbf{N Q}^{--}$to either the ${ }^{3} \mathrm{~B}_{1}$ or ${ }^{1} \mathrm{~B}_{1}$ states of $1,8-\mathbf{N Q}$.

\section{Assignment \# 1}

Due to the small geometry change from ${ }^{2} \mathrm{~A}_{2}$ to ${ }^{1} \mathrm{~A}_{1},{ }^{24}$ the $0-0$ peak for this electronic transition has the highest intensity in Figure 4. The FCFs decrease quickly for the rest of the vibrational peaks for ${ }^{2} \mathrm{~A}_{2} \rightarrow{ }^{1} \mathrm{~A}_{1}$, and the FCFs are consistent with the assignment of peak $\mathrm{X}$ to this transition.

The remaining, small vibrational peaks for ${ }^{2} \mathrm{~A}_{2} \rightarrow{ }^{1} \mathrm{~A}_{1}$ contribute to the intensity of peak B in the NIPE spectrum. However, most of the intensity of peak B in assignment $\# 1$ is due to $(0,0)$ vibrational peak for ${ }^{2} A_{2} \rightarrow{ }^{3} B_{2}$ state. As shown in Figure 4, the FCFs provide simulated shapes for the first two peaks in the NIPE spectrum of 1,8-NQ ${ }^{--}$that are consistent with the assignments, based on the EBEs in Table 1.

However, noticeable deviations in fitting the $\mathrm{X}$ and $\mathrm{B}$ bands in the $355 \mathrm{~nm}$ spectrum exist in assignment \#1. It is also clear that the fine structures in-between 3.1 and $3.2 \mathrm{eV}$ after band $\mathrm{B}$ in the 300 and $266 \mathrm{~nm}$ spectra cannot be fitted well in this assignment scheme. Most importantly, assignment \#1 does not account for the splitting observed in band $X$ in the experimental NIPE spectrum at $355 \mathrm{~nm}$.

\section{Assignment \# 2}

The significant discrepancies between the simulated spectra, based on assignment \# 1, and the experimental NIPE spectra led us to investigate a different set of spectral assignments. In assignment \#2 peak $\mathrm{X}$ at $2.965 \mathrm{eV}$ and peak $\mathrm{A}$ at $2.990 \mathrm{eV}$ in the $355 \mathrm{~nm}$ 


\begin{abstract}
NIPE spectrum are assigned to the ${ }^{1} \mathrm{~A}_{1}$ and ${ }^{3} \mathrm{~B}_{2}$ states, respectively. As shown in Figure 5, the simulated NIPE spectra, based on assignment scheme \# 2 provide a much better fit to the experimental 355, 300, and $266 \mathrm{~nm}$ NIPE spectra, compared to the fit based on assignment \# 1. More specifically, simulations based on assignment \# 2 not only account for the split peaks at $\mathrm{EBE} \sim 3.0 \mathrm{eV}$, which is resolved at $355 \mathrm{~nm}$, but also correctly fit all observed band positions (e.g., band $\mathrm{B}$ ) in $\mathrm{EBE}=3.0$ to 3.2 region.

Using assignment \#2, the experimental $E A$ of $1,8-\mathbf{N Q}$ is determined to be 2.965 $\mathrm{eV}$, again in excellent agreement with the CASPT2 calculated value of $2.957 \mathrm{eV}$. However, the new assignment yields a value of $\Delta E_{S T}=-0.6 \mathrm{kcal} / \mathrm{mol}$, which is about 1 $\mathrm{kcal} / \mathrm{mol}$ smaller in magnitude than $\Delta E_{S T}=-1.5 \mathrm{kcal} / \mathrm{mol}$ from assignment \#1 and 2 $\mathrm{kcal} / \mathrm{mol}$ smaller in magnitude than the calculated CASPT2 value of $\Delta E_{S T}=-2.6 \mathrm{kcal} / \mathrm{mol}$.
\end{abstract}




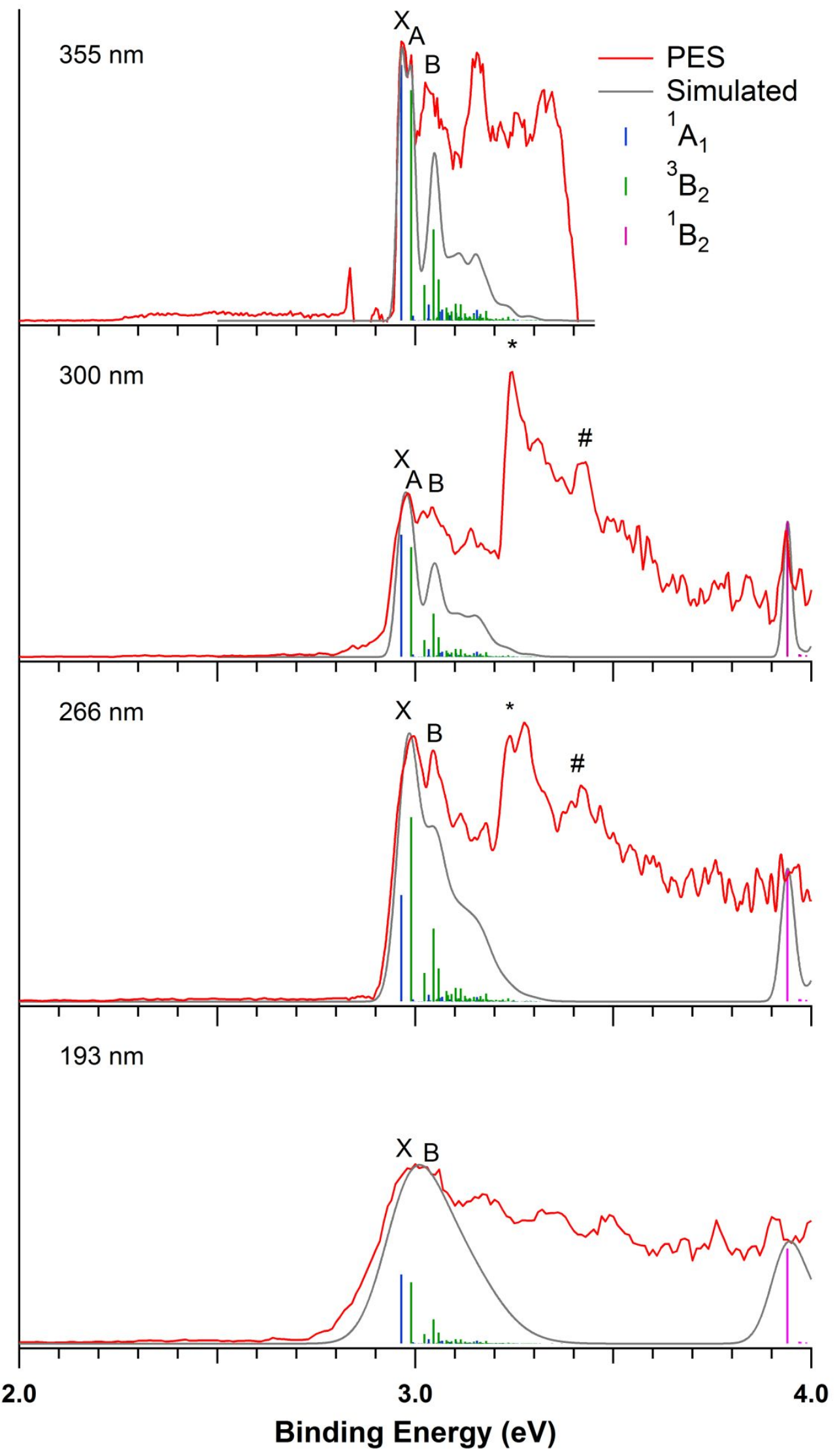


Figure 5. Simulated NIPE spectra based on assignment \# 2. The FWHMs of Gaussians for ${ }^{1} \mathrm{~A}_{1}$ and ${ }^{3} \mathrm{~B}_{2}$ peaks are set to $150 \mathrm{meV}$ for $193 \mathrm{~nm}$; $55 \mathrm{meV}$ for $266 \mathrm{~nm}$; $45 \mathrm{meV}$ for $300 \mathrm{~nm}$; and $25 \mathrm{meV}$ for $355 \mathrm{~nm}$. For the rest of the description of the spectral fitting procedure, see the caption for Figure 4.

The experimental value of $\Delta E_{S T}=-0.6 \mathrm{kcal} / \mathrm{mol}$ from assignment \#2 being 2 $\mathrm{kcal} / \mathrm{mol}$ smaller in magnitude than the CASPT2 value of $\Delta E_{S T}=-2.6 \mathrm{kcal} / \mathrm{mol}$ is not really surprising. In our previous study of $2,7-\mathbf{N Q}^{22}$ the energy difference between ${ }^{3} \mathrm{~B}_{2}$ and ${ }^{1} \mathrm{~A}_{1}$, predicted by CASPT2, was $\Delta E_{S T}=12.9 \mathrm{kcal} / \mathrm{mol}$; but the NIPE spectrum gave an energy difference between these two states of $16.4 \mathrm{kcal} / \mathrm{mol}$. The CASPT2 error of $-3.5 \mathrm{kcal} / \mathrm{mol}$, favoring the singlet, in $2,7-\mathbf{N Q}$, is nearly twice as large in magnitude as the CASPT2 error, again favoring the singlet, in 1,8-NQ.

The underestimation of the energy of the singlet, relative to the triplet, in 2,7-NQ suggests that, if the same type of error is made in 1,8-NQ, the calculated energy of ${ }^{1} \mathrm{~A}_{1}$, relative to ${ }^{3} \mathrm{~B}_{2}$, will also be too low. Therefore, the CASPT2 energy difference of -2.6 $\mathrm{kcal} / \mathrm{mol}$ between these two states in 1,8-NQ is likely to be too large in magnitude. This is, indeed, what our $355 \mathrm{~nm}$ NIPE spectrum shows.

If CASPT2 is likely to overestimate the energy of the triplet, relative to the singlet, how can we be sure that peak $X$ in our $355 \mathrm{~nm}$ NIPE spectrum does not belong to the ${ }^{3} \mathrm{~B}_{2}$ state and peak $A$ to the ${ }^{1} \mathrm{~A}_{1}$ state? The reversal of the assignments of these two peaks in the $355 \mathrm{~nm}$ NIPE spectrum would make the triplet the ground state of 1,8-NQ and give $\Delta E_{S T}=0.6 \mathrm{kcal} / \mathrm{mol}$. As shown in Figure 6 , assigning peak $\mathrm{X}$ to ${ }^{3} \mathrm{~B}_{2}$, and peak $\mathrm{A}$ to ${ }^{1} \mathrm{~A}_{1}$ leads to significant deterioration in the fit between both the position and the intensity of peak $B$ in the simulated spectrum and in the 355,300 , and $266 \mathrm{~nm}$ experimental NIPE spectra. Therefore, the possible assignment of peak $\mathrm{X}$ to ${ }^{3} \mathrm{~B}_{2}$, and peak $\mathrm{A}$ to ${ }^{1} \mathrm{~A}_{1}$ is ruled out by the position of peak B, relative to peaks $\mathrm{X}$ and $\mathrm{A}$, in the experimental NIPE spectra. 

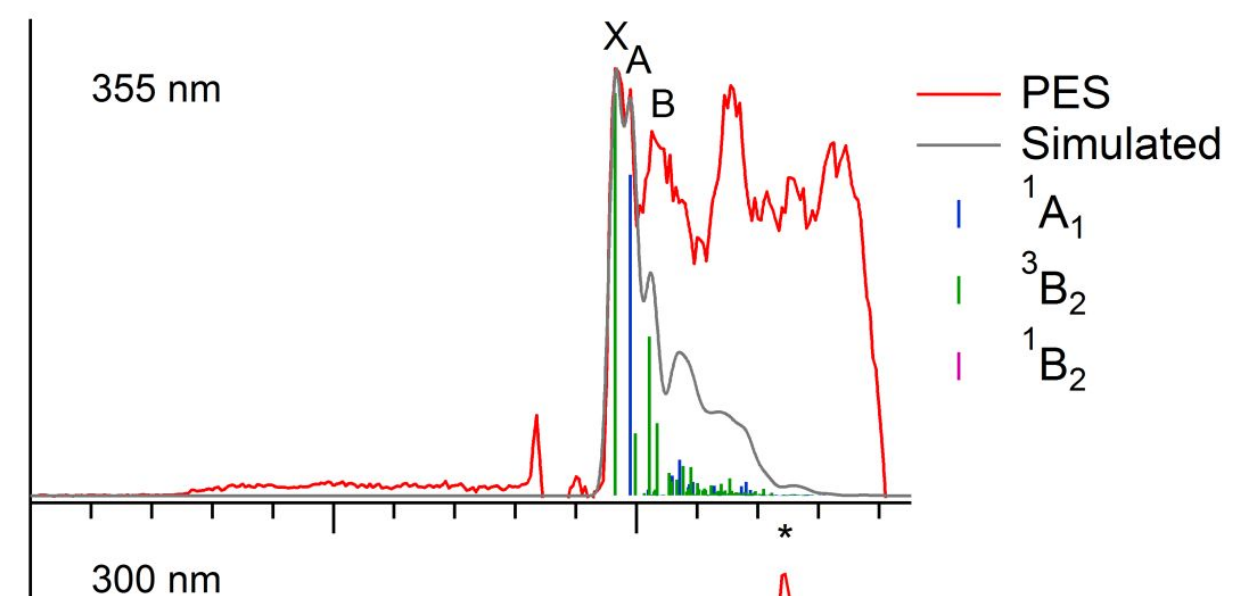

$300 \mathrm{~nm}$
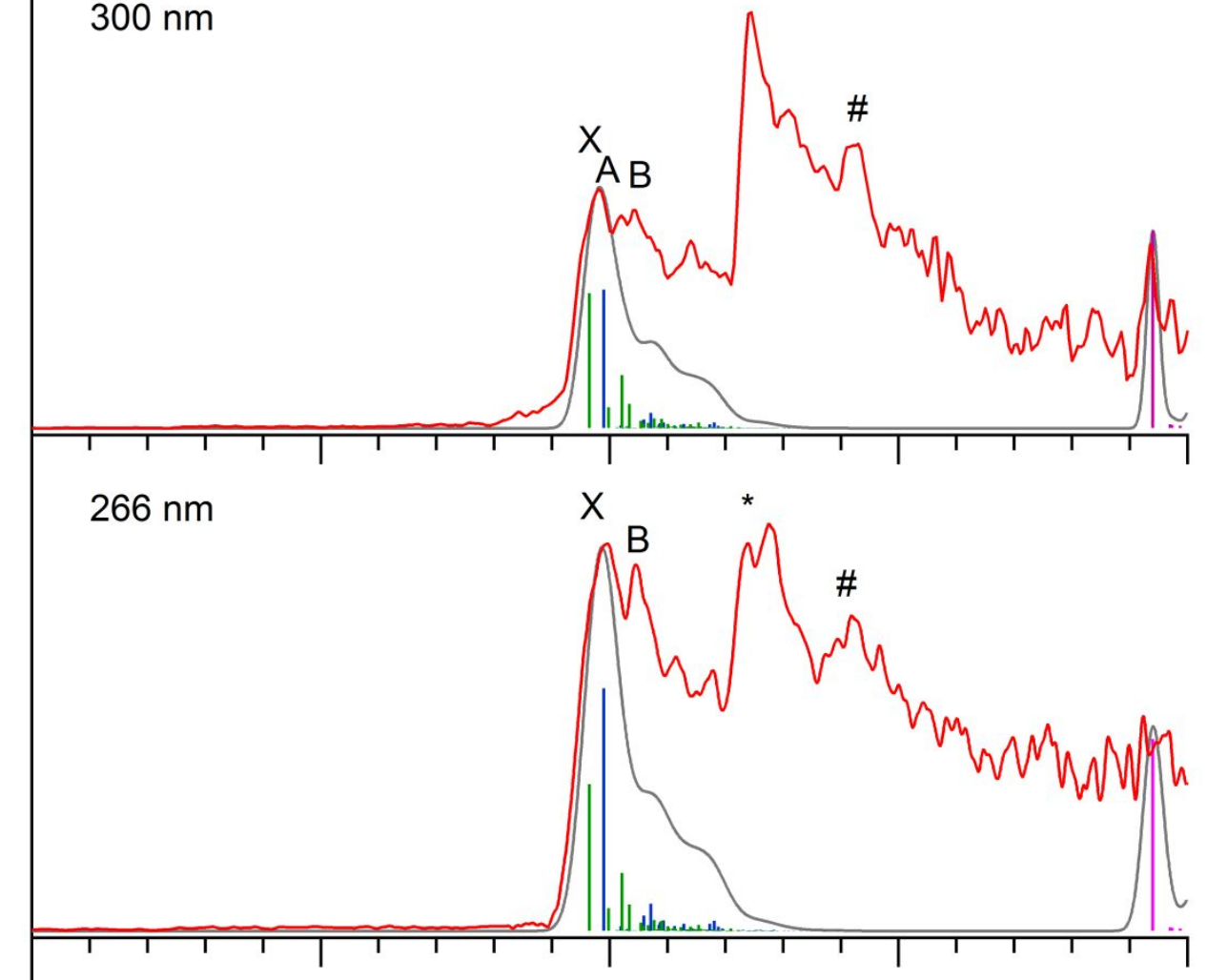

$193 \mathrm{~nm}$

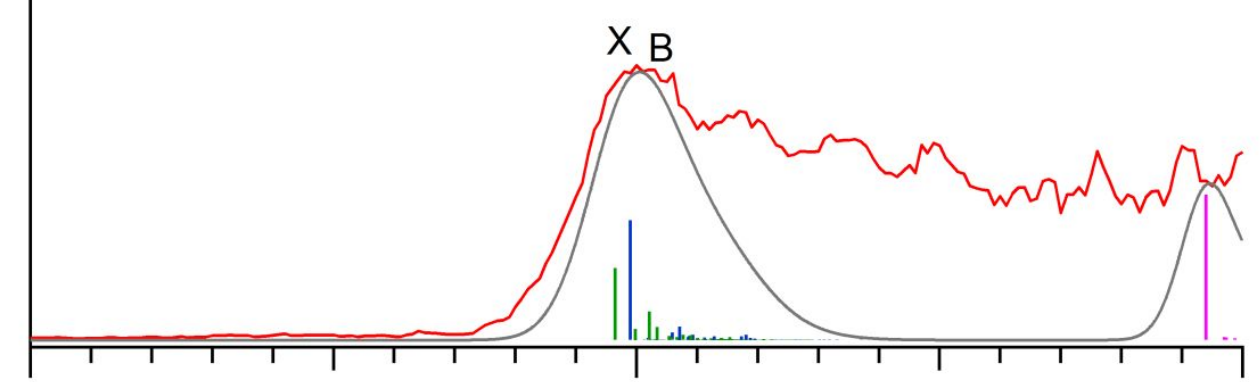

2.0

3.0

4.0

Binding Energy (eV) 
Figure 6. Simulated NIPE spectra by assigning peak $\mathrm{X}$ to ${ }^{3} \mathrm{~B}_{2}$, and peak $\mathrm{A}$ to ${ }^{1} \mathrm{~A}_{1}$ states. The rest of the description of the spectral fitting procedure, see the caption for Figure 5.

As shown in Figures 4 and 5, our CASPT2/cc-pVDZ vibrational analysis predicts a strong progression (of $453 \mathrm{~cm}^{-1}$ ) in the ${ }^{3} \mathrm{~B}_{2}$ state but not in the ${ }^{1} \mathrm{~A}_{1}$ state. The first (X) and third (B) peaks in the $355 \mathrm{~nm}$ NIPE spectrum are separated by $605 \mathrm{~cm}^{-1}$; whereas the second (A) and third (B) peaks are separated by $444 \mathrm{~cm}^{-1}$. The fact that the separation of $444 \mathrm{~cm}^{-1}$ between the second and third peaks is very close to that of $453 \mathrm{~cm}^{-1}$, calculated for the triplet, leads us to assign these two peaks as both belonging to the ${ }^{3} \mathrm{~B}_{2}$ state. Therefore, we assign the lowest energy peak $(X)$ in the NIPE spectrum as belonging to the ${ }^{1} \mathrm{~A}_{1}$ state, thus confirming the prediction that $1,8-\mathrm{NQ}$ has a singlet ground state.

Why does the triplet have a vibrational progression of $444 \mathrm{~cm}^{-1}$ in the NIPE spectrum but the singlet does not? The low frequency of this vibration indicates that it is a bending vibration. Our CASPT2/cc-pVDZ vibrational analysis shows that the bending vibration with a calculated frequency of $453 \mathrm{~cm}^{-1}$ affects many bond angles, but it has its largest effect on the bond angle at the bridgehead carbon $(\mathrm{C} 10)$ at the bottom of the molecule, which is bonded to $\mathrm{C} 4$ and $\mathrm{C} 5$. The calculated $\mathrm{C} 4-\mathrm{C} 10-\mathrm{C} 5$ bond angle in the ${ }^{2} \mathrm{~A}_{2}$ state of the radical anion is $117.1^{\circ}$, which is close to that of $116.1^{\circ}$ in the ${ }^{1} \mathrm{~A}_{1}$ state, but is $2.3^{\circ}$ smaller than the calculated C4-C10-C5 bond angle of $119.4^{\circ}$ in the ${ }^{3} \mathrm{~B}_{2}$ state. The much larger change in the C4-C10-C5 bond angle for ${ }^{2} \mathrm{~A}_{2} \longrightarrow{ }^{3} \mathrm{~B}_{2}$ than for ${ }^{2} \mathrm{~A}_{2}$ $\longrightarrow{ }^{1} \mathrm{~A}_{1}$ is the reason why a strong vibrational progression, which affects this angle, is seen in the ${ }^{3} \mathrm{~B}_{2}$ state, but not in the ${ }^{1} \mathrm{~A}_{1}$ state.

\section{Provisional Assignments for Peaks * and \#}

As shown in Table 1, the EBEs of peaks * and \# in the NIPE spectra in Figures 3 and 4 align well with the EBEs computed for formation of the ${ }^{3} \mathrm{~B}_{1}$ and ${ }^{1} \mathrm{~B}_{1}$ states of 1,8 NQ. These peaks are intense and appear to come from electronic transitions that have large FCFs. However, the FCFs for formation of the ${ }^{3} B_{1}$ and ${ }^{1} B_{1}$ states of $1,8-N Q$ from the ${ }^{2} \mathrm{~A}_{2}$ state of $1,8-\mathbf{N Q}^{--}$are not calculated to be large. They are, in fact, calculated to be zero! 
There is a good physical reason why the FCFs are computed to be zero. The transitions from ${ }^{2} \mathrm{~A}_{2}$ to ${ }^{3} \mathrm{~B}_{1}$ and ${ }^{1} \mathrm{~B}_{1}$ involve the loss of an electron from the $\mathrm{b}_{2} \sigma \mathrm{MO}$. As shown in Figure 2, this MO is strongly O-O antibonding. Consequently, these transitions result in a huge decrease of $\sim 0.6 \AA$ in the O-O distance. As a result there is no overlap between some of the vibrational wave functions of the ${ }^{2} \mathrm{~A}_{2}$ state of $1,8-\mathrm{NQ}^{--}$and the corresponding vibrational wave functions of the ${ }^{3} \mathrm{~B}_{1}$ and ${ }^{1} \mathrm{~B}_{1}$ states of $1,8-\mathbf{N Q}$.

Why, then, do peaks * and \#, whose EBEs correspond closely to those computed for ${ }^{3} \mathrm{~B}_{1}$ and ${ }^{1} \mathrm{~B}_{1}$, have large intensities? An attractive explanation is that these peaks arise from a transition from the ${ }^{2} \mathrm{~A}_{2}$ ground state of $1,8-\mathrm{NQ}^{--}$to the ${ }^{2} \mathrm{~B}_{2}$ excited state, which is computed to be higher by $13.2 \mathrm{kcal} / \mathrm{mol} .{ }^{24}$ Like the ${ }^{3} \mathrm{~B}_{1}$ and ${ }^{1} \mathrm{~B}_{1}$ states of $1,8-\mathbf{N Q}$, the ${ }^{2} \mathrm{~B}_{2}$ excited state of $1,8-\mathbf{N Q}^{\circ-}$ has only one electron in the $\mathrm{b}_{2} \sigma \mathrm{MO}$; so the O-O distance in ${ }^{2} \mathrm{~B}_{2}$ of $2.241 \AA$ is very close to the $\mathrm{O}-\mathrm{O}$ distances of 2.201 and $2.232 \AA$ in the ${ }^{3} \mathrm{~B}_{1}$ and ${ }^{1} \mathrm{~B}_{1}$ states, respectively. Consequently, the FCFs for ${ }^{2} \mathrm{~B}_{2} \rightarrow{ }^{3} \mathrm{~B}_{1}$ and ${ }^{1} \mathrm{~B}_{1}$, unlike those for ${ }^{2} \mathrm{~A}_{2}$ $\rightarrow{ }^{3} \mathrm{~B}_{1}$ and ${ }^{1} \mathrm{~B}_{1}$, should be far from zero.

In order to confirm that this is, indeed, the case, we have computed the FCFs for ${ }^{2} \mathrm{~B}_{2} \rightarrow{ }^{3} \mathrm{~B}_{1}$ and ${ }^{1} \mathrm{~B}_{1}$. The resulting vibrational peaks are shown in Figure 7 , superimposed on the experimental 300 and $266 \mathrm{~nm}$ NIPE spectra. 


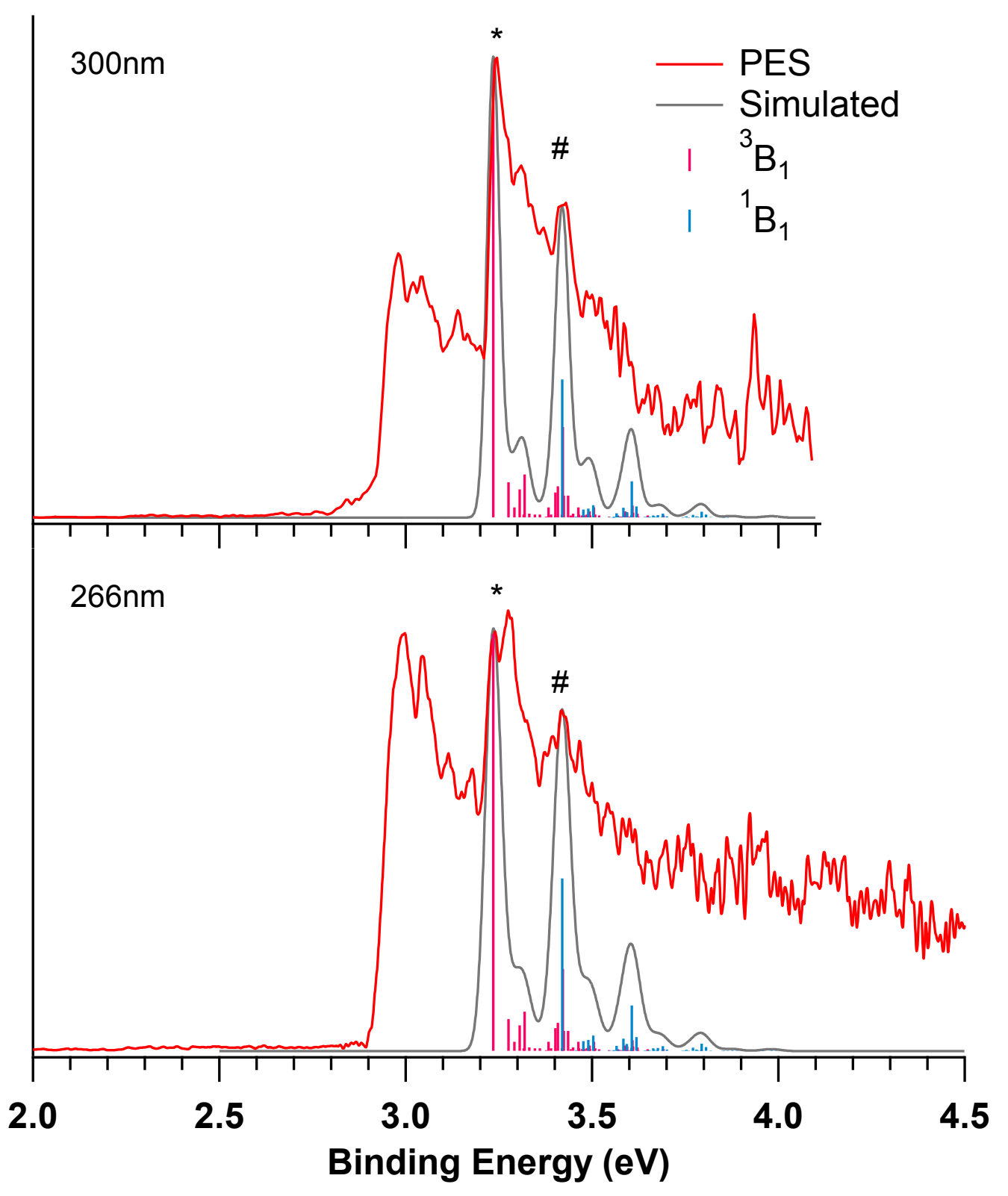

Figure 7. Simulated spectra for a transition from the ${ }^{2} \mathrm{~B}_{2}$ excited state of $1,8-\mathrm{NQ}^{-}$to the ${ }^{3} \mathrm{~B}_{1}$ and ${ }^{1} \mathrm{~B}_{1}$ excited states of 1,8-NQ, using the calculated CASPT2/aug-cc-pVDZ stick spectra, convoluted with Gaussian line broadening with the FWHMs of Gaussians set to $50 \mathrm{meV}$. The simulated spectra containing all five states, i.e., ${ }^{1} \mathrm{~A}_{1},{ }^{3} \mathrm{~B}_{2},{ }^{3} \mathrm{~B}_{1},{ }^{1} \mathrm{~B}_{1}$, and ${ }^{1} \mathrm{~B}_{2}$, superimposed onto the experimental 300 and 266 nm spectra of 1,8-NQ-, are provided in Figure S3 of the Supporting Information. 
Of course, the $E B E \mathrm{~s}$ for ${ }^{2} \mathrm{~A}_{2} \rightarrow{ }^{2} \mathrm{~B}_{2}$, followed by resonant autodetachment of the ${ }^{2} \mathrm{~B}_{2}$ excited state of $1,8-\mathbf{N Q}^{--}$to the ${ }^{3} \mathrm{~B}_{1}$ and ${ }^{1} \mathrm{~B}_{1}$ states of $1,8-\mathbf{N Q}$ are exactly the same as the EBEs for formation of these two states of 1,8-NQ directly from the ${ }^{2} \mathrm{~A}_{2}$ state of $1,8-$ NQ $^{--}$. Consequently, the FCF simulations of the vibrational structure for the formation of the ${ }^{3} \mathrm{~B}_{1}$ and ${ }^{1} \mathrm{~B}_{1}$ states of $1,8-\mathbf{N Q}$ are shown in Figure 7 under the * and \# peaks, to which these states of 1,8-NQ are assigned.

The proposal that resonant autodetachment is responsible for formation of peaks * and \# in the NIPE spectrum of 1,8-NQ ${ }^{-}$is supported by the fact that resonant autodetachment has been frequently observed in anions of aromatic molecules. ${ }^{16,22,32}$ The intensities of the peaks formed by resonant autodetachment have been found to be highly dependent on the photon energy; and, indeed, as can be seen in Figure 3, the intensities of peaks * and \# do change a lot with different photon energies. In fact, in the $193 \mathrm{~nm}$ NIPE spectrum of $1,8-\mathbf{N Q}^{\circ-}$, it appears that there are no peaks at the positions of * and \#, where peaks are seen in the $266 \mathrm{~nm}$ and $300 \mathrm{~nm}$ NIPE spectra.

\section{Summary and Conclusions}

The $355 \mathrm{~nm}$ NIPE spectrum of 1,8-NQ ${ }^{-}$has confirmed the theoretical prediction that a singlet is the ground state of 1,8-NQ. The FCFs, calculated from the CASPT2/augcc-pVDZ optimized geometries, normal modes, and frequencies successfully simulated the appearance of these two peaks. Based on the good agreement between the $444 \mathrm{~cm}^{-1}$ spacing between peaks A and B in the $355 \mathrm{~nm}$ NIPE spectrum and the calculated vibrational progression of $453 \mathrm{~cm}^{-1}$ in the ${ }^{3} \mathrm{~B}_{2}$ state, peaks $A$ and $B$ are assigned to the ${ }^{3} B_{2}$ excited state of $1,8-\mathbf{N Q}$, and peak $\mathrm{X}$ is assigned to the ${ }^{1} \mathrm{~A}_{1}$ ground state.

Peak $\mathrm{X}$ has $E B E=2.965 \mathrm{eV}$, and peak A has $E B E=2.990 \mathrm{eV}$. Thus, the experimental value of $\Delta E_{S T}$ in $1,8-\mathrm{NQ}$ is $-0.025 \mathrm{eV}(-0.6 \mathrm{kcal} / \mathrm{mole})$. This value of $\Delta E_{S T}$ $=-0.6 \mathrm{kcal} / \mathrm{mol}$ in $1,8-\mathrm{NQ}$ is $2 \mathrm{kcal} / \mathrm{mol}$ smaller in magnitude than the value of $\Delta E_{S T}=-$ $2.6 \mathrm{kcal} / \mathrm{mole}$ that is predicted by CASPT2 calculations. ${ }^{24}$ In $1,8-\mathbf{N Q}$, as in 2,7-NQ, ${ }^{22}$ CASPT2 underestimates the energy of the ${ }^{1} \mathrm{~A}_{1}$ state, relative to the ${ }^{3} \mathrm{~B}_{2}$ state. 
The next two peaks, * and \#, in the NIPE spectrum of $1,8-\mathbf{N Q}^{\circ-}$ can be assigned to, respectively, the ${ }^{3} \mathrm{~B}_{1}$ and ${ }^{1} \mathrm{~B}_{1}$ states on the basis of the good correspondence between the $E B E$ s measured for these two peaks and those computed for the ${ }^{3} \mathrm{~B}_{1}$ and ${ }^{1} \mathrm{~B}_{1}$ states.

Because these two states each have only one electron in the $\mathrm{O}-\mathrm{O}$ antibonding $\mathrm{b}_{2} \mathrm{MO}$, these states have much smaller $\mathrm{O}-\mathrm{O}$ distances than the ${ }^{2} \mathrm{~A}_{2}$ ground state of $1,8-\mathbf{N Q}^{\circ-}$. Consequently, the calculated FCFs for ${ }^{2} \mathrm{~A}_{2} \rightarrow{ }^{3} \mathrm{~B}_{1}$ and ${ }^{1} \mathrm{~B}_{1}$ are zero.

Formation of ${ }^{3} \mathrm{~B}_{1}$ and ${ }^{1} \mathrm{~B}_{1}$ from ${ }^{2} \mathrm{~A}_{2}$ is postulated to occur via an indirect pathway, involving excitation of the ${ }^{2} \mathrm{~A}_{2}$ ground state of $1,8-\mathrm{NQ}^{--}$to the low-lying ${ }^{2} \mathrm{~B}_{2}$ excited state, which undergoes resonant autodetachment to form ${ }^{3} \mathrm{~B}_{1}$ and ${ }^{1} \mathrm{~B}_{1}$. Because, like the ${ }^{3} \mathrm{~B}_{1}$ and ${ }^{1} \mathrm{~B}_{1}$ states of $1,8-\mathbf{N Q}$, the ${ }^{2} \mathrm{~B}_{2}$ state of $1,8-\mathbf{N Q}^{--}$has only one electron in the O-O antibonding $\mathrm{b}_{2} \mathrm{MO}$, the FCFs for ${ }^{2} \mathrm{~B}_{2} \rightarrow{ }^{3} \mathrm{~B}_{1}$ and ${ }^{1} \mathrm{~B}_{1}$ are non-zero. Experimental evidence for the operation of this resonant autodetachment pathway to form ${ }^{3} \mathrm{~B}_{1}$ and ${ }^{1} \mathrm{~B}_{1}$, comes from the dependence of the intensities of the * and \# peaks in the NIPE spectrum of 1,8$\mathbf{N Q}^{--}$on the energy of the laser used for electron detachment.

Supporting Information. The 20 K NIPE spectra of 1,8-NQ ${ }^{--}$at $355,266 \mathrm{~nm}$ containing contributions from an unknown species with identical mass-to-charge ratio; The simulated NIPE spectra of $\mathbf{1 , 8}$-NQ with ${ }^{1} \mathrm{~A}_{1},{ }^{3} \mathrm{~B}_{2},{ }^{3} \mathrm{~B}_{1},{ }^{1} \mathrm{~B}_{1}$, and ${ }^{1} \mathrm{~B}_{2}$ states, superimposed onto the experimental $266 \mathrm{~nm}$ and $300 \mathrm{~nm}$ spectra.

\section{Author Information}

\section{Corresponding Authors}

Weston T. Borden: Weston.Borden@unt.edu

Xue-Bin Wang: Xuebin.wang@pnnl.gov

\section{Notes}


The authors declare no competing financial interest

\section{Acknowledgement}

WTB acknowledges the generous support of his research by Grant B0027 from the Robert A. Welch Foundation and dedicates this paper to Prof. Helmut Schwarz on the occasion of his $75^{\text {th }}$ birthday. The photoelectron spectroscopy work done at PNNL was supported by U.S. Department of Energy (DOE), Office of Science, Office of Basic Energy Sciences, Division of Chemical Sciences, Geosciences, and Biosciences (XBW), and performed in EMSL, a national scientific user facility sponsored by DOE's Office of Biological and Environmental Research and located at Pacific Northwest National Laboratory, which is operated by Battelle Memorial Institute for the DOE.

\section{References}

1. Salem, L.; Rowland, C. The Electronic Properties of Diradicals. Angew. Chem., Int. Ed. 1972. 11, 92-111.

2. Borden, W.T. Ed. Diradicals, 1982, Wiley-Interscience, New York, 1982.

3. Osamura, Y.; Borden, W.T.; Morokuma, K. Structure and Stability of Oxyallyl. An MCSCF Study. J. Am. Chem. Soc. 1984. 106, 5112-5115.

4. Coolidge, M. B.; Yamashita, K.; Morokuma, K.; Borden, W. T. Ab initio MCSCF and CI Calculations of the Singlet-Triplet Energy Differences in Oxyallyl and in Dimethyloxyallyl. J. Am. Chem. Soc. 1990. 112,1751-1754.

5. Ervin, K. M.; Lineberger, W.C. in Advances in Gas Phase Ion Chemistry. 1992, JAI Press: Greenwich. p. 121-166.

6. Wenthold, P.G.; Hu, J.; Squires, R. R.; Lineberger, W. C. Photoelectron Spectroscopy of the Trimethylenemethane Negative Ion. The Singlet-Triplet Splitting of Trimethylenemethane. J. Am. Chem. Soc. 1996. 118, 475-476.

7. Wenthold, P.G.; Kim, J.B.; Lineberger, W.C. Photoelectron Spectroscopy of $m$ Xylylene Anion. J. Am. Chem. Soc.1997. 119, 1354-1359. 
8. Ichino, T.; Villano, S. M.; Gianola, A. J.; Goebbert, D. J.; Velarde, L.; Sanov, A.; Blanksby, S. J.; Zhou, X.; Hrovat, D. A.; Borden, W. T.; Lineberger, W. C. The Lowest Singlet and Triplet States of the Oxyallyl Diradical. Angew. Chem., Int. Ed. 2009. 48, 8509-8511.

9. Lineberger, W. C.; Borden, W. T. The Synergy between Qualitative Theory, Quantitative Calculations, and Direct Experiments in Understanding, Calculating, and Measuring the Energy Differences between the Lowest Singlet and Triplet States of Organic Diradicals. Phy. Chem. Chem. Phys. 2011. 13,11792-11813.

10. Abe, M. Diradicals. Chem. Rev. 2013. 113, 7011-7088.

11. Hrovat, D. A.; Hou, G. L.; Wang, X. B.; Borden, W. T. Negative Ion Photoelectron Spectroscopy Confirms the Prediction that 1,2,4,5-Tetraoxatetramethylenebenzene Has a Single Groud. J. Am. Chem. Soc. 2015, 137, 9094-9099.

12. Borden, W.T. Diradicals - A Fifty Year Fascination, in The Foundations of Physical Organic Chemistry: Fifty Years of the James Flack Norris Award. 2015, American Chemical Society. p. 251-303.

13. Marks, J.; Comita, P. B.; Brauman, J. I. Threshold Resonances in Electron Photodetachment Spectra. Structural Evidence for Dipole-Supported States. J. Am. Chem. Soc. 1985, 107, 3718-3719.

14. Fort, R. C. Jr.; Getty, S. J.; Hrovat, D. A.; Lahti, P. M.; Borden, W. T. Ab Initio Calculations on $m$-Quinone. The Ground State Is a Triplet. J. Am. Chem. Soc. 1992. $114,7549-7552$.

15. Itoh, T. Low-Lying Electronic States, Spectroscopy, and Photophysics of Linear Para Acenequinones. Chem. Rev. 1995, 95, 2351-2368.

16. Schiedt, J.; Weinkauf, R. Resonant Photodetachment via Shape and Feshbach Resonances: p-Benzoquinone Anions as a Model System. J. Chem. Phys. 1999, 110, 304-314.

17. Fattahi, A.; Kass, S. R.; Liebman, J. F.; Matos, M. A. R.; Miranda, M. S.; Morais, V. M. F. The Enthalpies of Formation of $o_{-}^{-}, m-$, and $p$-Benzoquinone: Gas-Phase Ion Energetics, Combustion Calorimetry, and Quantum Chemical Computations Combined. J. Am. Chem. Soc. 2005, 127, 6116-6122. 
18. Fu, Q.A.; Yang, J.L.; Wang, X.B. On the Electronic Structures and Electron Affinities of the $m$-Benzoquinone (BQ) Diradical and the $o-, p$-BQ Molecules: A Synergetic Photoelectron Spectroscopic and Theoretical Study. J. Phys. Chem. A 2011,115, 3201-3207.

19. Horke, D. A.; Li, Q.; Blancafort, L.; Verlet. J. R. R. Ultrafast Above-Threshold Dynamics of the Radical Anion of a Prototypical Quinone Electron-Acceptor. Nat. Chem. 2013, 5, 711-717.

20. Chen, B.; Hrovat, D. A.; Deng, S. H. M.; Zhang, J.; Wang, X. B.; Borden, W. T. The Negative Ion Photoelectron Spectrum of meta-Benzoquinone Radical Anion (MBQ--): A Joint Experimental and Computational Study. J. Am. Chem. Soc. 2014, 136, 3589-3596.

21. Hrovat, D.A.; Wang, X.B.; Borden, W.T. Calculations of the Relative Energies of the Low-lying Electronic States of 2,7-Naphthoquinodimethane and 2,7Naphthoquinone. Substitution of Oxygen for $\mathrm{CH}_{2}$ is Predicted to Increase the Singlet-Triplet Energy Difference $\left(\Delta \mathrm{E}_{\mathrm{ST}}\right)$. J. Phy. Org. Chem. 2018, e3824.

22. Yang, Z.; Hrovat, D. A.; Hou, G. L.; Borden, W. T.; Wang, X. B. Negative Ion Photoelectron Spectroscopy Confirms the Prediction of the Relative Energies of the Low-Lying Electronic States of 2,7-Naphthoquinone. J. Phys. Chem. A 2018, 122, 4838-4844.

23. Berson, J.A. in Reactive Intermediate Chemistry; Moss, R.S. Platz, M.S., Jones, M. Jr., Eds., Wiley Interscience, New Jersey, 2004, p. 165.

24. Hrovat, D. A.; Wang, X.B.; Borden, W. T. Calculations on 1,8-Naphthoquinone Predict that the Ground State of this Diradical Is a Singlet. J. Comput. Chem. 2019, 40, 119-126.

25. Wang, X. B.; Wang, L. S. Development of a Low-temperature Photoelectron Spectroscopy Instrument Using an Electrospray Ion Source and a Cryogenically Controlled Ion Trap. Rev. Sci. Instrum. 2008, 79, 073108.

26. Hanstorp, D.; Gustafsson, M. Determination of the Electron Affinity of Iodine. $J$. Phys. B: At., Mol. Opt. Phys. 1992, 25, 1773-1783. 
27. Wang, X. B.; Wang, L. S. Photodetachment of Free Hexahalogenometallate Doubly Charged Anions in the Gas Phase: [ML6] ${ }^{2-},(\mathrm{M}=\mathrm{Re}, \mathrm{Os}, \mathrm{Ir}, \mathrm{Pt} ; \mathrm{L}=\mathrm{Cl}$ and Br). J. Chem. Phys. 1999, 111, 4497-4509.

28. Dunning, T.H. Gaussian Basis Sets for Use in Correlated Molecular Calculations. I. The Atoms Boron through Neon and Hydrogen. J. Chem. Phys. 1989, 90, 10071023.

29. Kendall, R.A.; Dunning, T.H.; Harrison, R.J. Electron Affinities of the First-row Atoms Revisited. Systematic Basis Sets and Wave Functions. J. Chem. Phys. 1992, 96, 6796-6806.

30. Aquilante, F.; Autschbach, J.; Carlson, R. K.; Chibotaru, L. F.; Delcey, M. G.; De Vico, L.; Fdez. Galván, I.; Ferré, N.; Frutos, L. M.; Gagliardi, L.; et al. Molcas 8: New Capabilities for Multiconfigurational Quantum Chemical Calculations Across the Periodic Table. J. Comput. Chem. 2016, 37, 506-541.

31. Mozhayskiy, V.A., Krylov, A.I., ezSpectrum 3.0, see http://iopenshell.usc.edu/downloads (accessed April 2017).

32. Stanley, L. H.; Anstoter, C. S.; Verlet, J. R. R., Resonances of the Anthracenyl Anion Probed by Frequency-resolved Photoelectron Imaging of Collision-induced Dissociated Anthracene Carboxylic Acid. Chem. Sci. 2017, 8, 3054-3061. 


\section{TOC graphic}

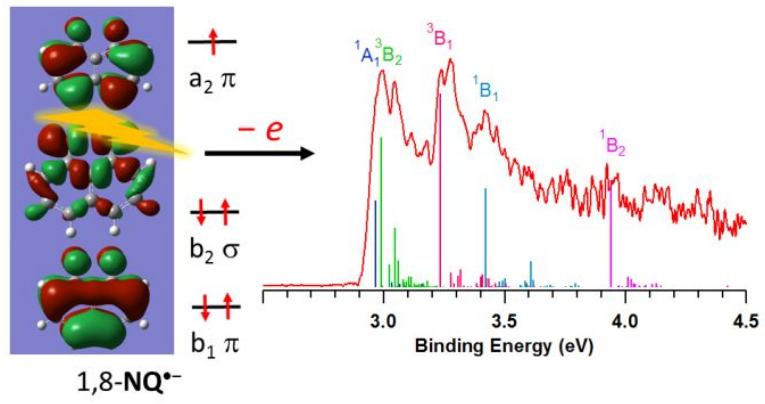

